\title{
HPLC analysis and in vitro study of the extract from Punica granatum peel
}

\author{
Min San Kim* and Chang-Shik Choi ${ }^{\dagger *}$ \\ *Department of Pharmaceutical Engineering, International University of Korea, Jinju, Kyeongnam 660-759, Korea \\ ${ }^{\dagger}$ Department of Oriental Medicine Fermentation, Far East University, Eumseong, Chungbuk 369-851, Korea
}

ABSTRACT : The extract of Punica granatum peel was separated and confirmed by HPLC, and punicalagin, one of the extract, was better antibacterial activity against Salmonella.

Punica granatum peel is used to treat infections of human sexual organs as well as mastitis, acne, folliculitis, pile, allergic dermatitis, tympanitis, scalds, diarrhea, dysentery, and as also acts an antioxidant. ${ }^{1}$ It contains very rich ellagic acid derivatives such as the ellagitannins punicalagin as well as some amounts of punicalin, gallic acid, ellagic acid

Punica granatum peel is a polyphenol naturally occurring in many plant foods in certain fruits and nuts such as carrots, tomatoes, raspberries, strawberries, walnuts, longan seeds, mangoes kernel and pomegranates. ${ }^{2}$
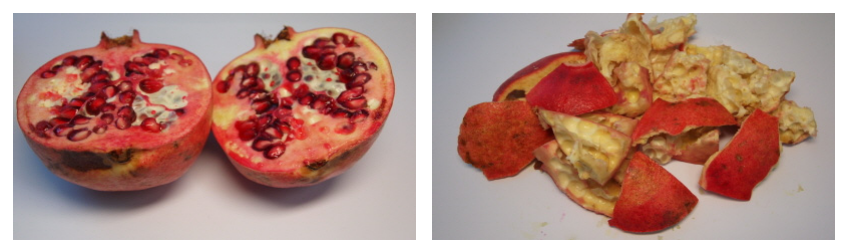

Fig 1. Punica granatum L.

Ellagic acid has a variety of biological activities, including potent anti-oxidant, anti-cancer, antiproliferative, chemopreventive, anti-atherogenic and anti -mutagen properties in a number of in vitro and small animal models. ${ }^{3}$ Ellagic acid is able to inhibit breast cancer cell by inducing apoptosis through regulation of matrix metalloproteinases, vascular endothelial growth factor expression, angiogenesis. In addition, it prevents and repairs DNA damage.

*To whom correspondence should be addressed.

E-mail: cschoi@kdu.ac.kr, kms7594@hanmail.net
Gallic acid, a polyhydroxyphenolic compound, is one of the major bioactive compounds. It is naturally occurring in many plants and fruits such as gallnuts, sumacs, oak barks, green tea, pineapples, strawberries, bananas, lemons, apple-peels, grapes and in red and white wine. ${ }^{4}$ To have gallic acid is reported anticarcinogenic, anti-mutagenic, anti-allergic, antiinflammatory, anti-bacterial, anti-cancer and antioxidant $^{5}$ pharmacological activities.<smiles>O=c1oc2c(O)c(O)cc3c(=O)oc4c(O)c(O)cc1c4c23</smiles><smiles>O=C(O)c1cc(O)c(O)c(O)c1</smiles>

Fig 2. Chemical structure of ellagic acid and gallic acid

Punicalagin is a large polyphenolic compound that is an isomer of 2,3-(S)-hexahydroxydiphenoyl-4,6-(S,S)gallagyl-D-glucose and structurally belongs to the ellagitannins, hydrolysable tannins with a molecular weight of $1084 .^{6}$ These compounds impart the characteristic yellow colour of pomegranate husk, and are extracted with the juice during processing. ${ }^{7}$ It is major bioactive compound isolated and purified from Punica granatium and antioxidant health benefits. ${ }^{8}$ It is widely distributed in plants, such as stem bark of Combretum molle, ${ }^{9}$ Terminalia citrina, ${ }^{10}$ Terminalia mollis and Terminalia brachystemma. ${ }^{11}$ Punicalagin was reported to inhibit the proliferation of several human colon cancer cell lines and induce their apoptosis at high concentrations ${ }^{12}$ and pharmacological activities including anti-inflammatory, ${ }^{13}$ hepatoprotective, ${ }^{14}$ and anti-genotoxic activities. ${ }^{15}$ 


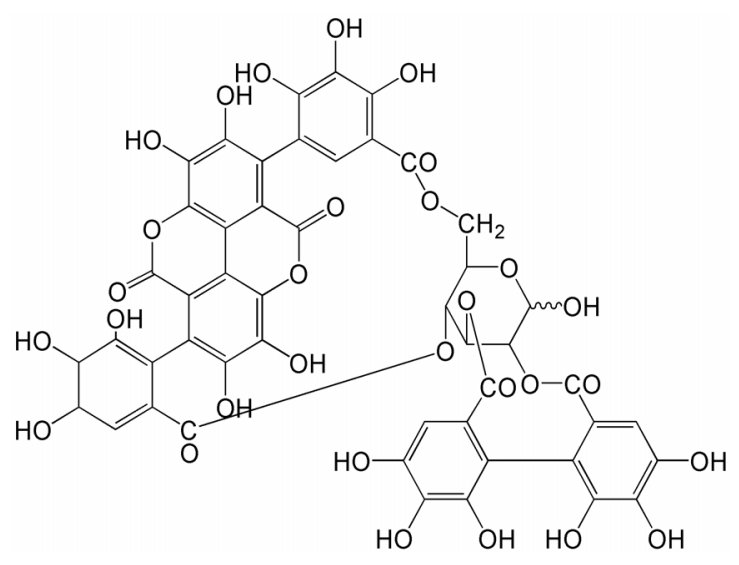

Fig 3. Chemical structure of punicalagin

We separated and confirmed gallic acid, ellagic acid, and punicalagin by HPLC and carried out simple in vitro study on the antibacterial activity against Salmonella. Herein, we report the HPLC study and interesting antibacterial activity.

To prepare the sample for HPLC experiment, Punica granatum peel was airdried in the dark at room temperature(RT) and then ground into a powder using a mechanical grinder. Approximately $500 \mathrm{~g}$ of the powdered materials were then boiled in $1500 \mathrm{ml}$ of EtOH for $3 \mathrm{~h}$. The solvent was then removed under reduced pressure in a rotary evaporator $\left(\mathrm{N}^{-}\right.$ 1000S, EYELA, Japan) and dissolved in water or $50 \%$ dimethyl sulfoxide (DMSO) prior to use.

The HPLC system consisted of a Shimadzu LC-6A model (Shimadzu, Tokyo, Japan), with a column of ODS-C18 (4.6 x $250 \mathrm{~mm}, 5 \mathrm{~mm})$ and a detection of SPD- 6AV with a sensitivity of 0.04 AUFS and a wavelength of $254 \mathrm{~nm}$. Elution was carried out at a flow rate of $0.8 \mathrm{ml} / \mathrm{min}$ under a linear gradient of acetonitrile (solvent A) and $\mathrm{H}_{2} \mathrm{O}$ with $1 \%$ formic acid (solvent B) from $5 \% \mathrm{~A}$ to $100 \% \mathrm{~A}$ in $50 \mathrm{~min}$. The Punica granatum peel extract was dissolved in a mixture of methanol and water $(6: 4 \mathrm{v} / \mathrm{v})$, and $20 \mu 1$ was injected into the HPLC. The presence of gallic acid and ellagic acid was confirmed by the same retention time of their standards (Sigma Chemical Co, St. Louis, USA). The obtained chromatogram is shown in Fig. 4(16).
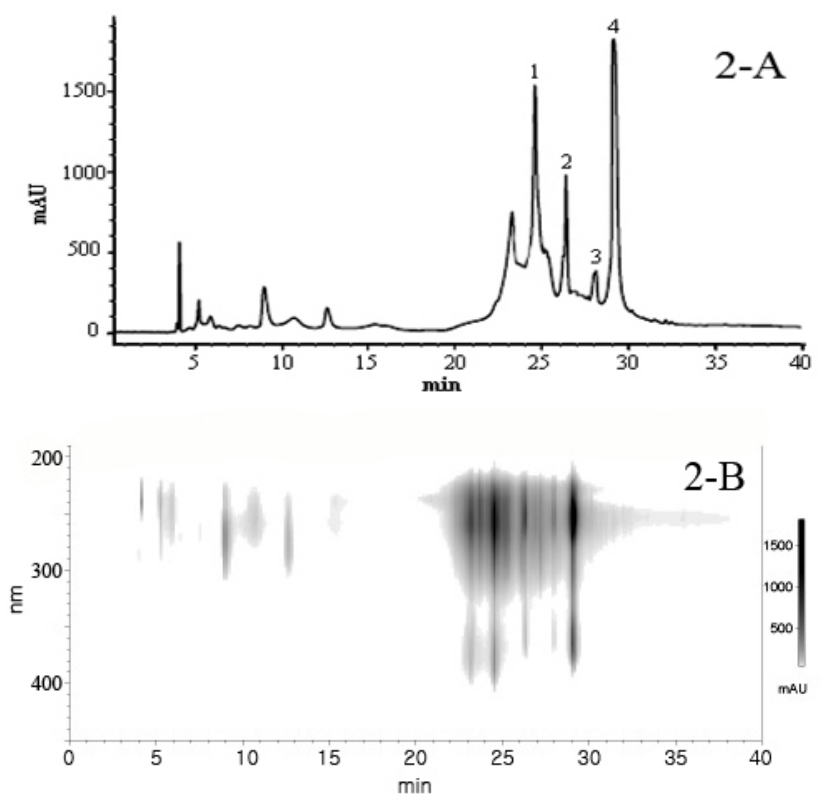

Fig. 4. HPLC analyses of crude extract from Punica granatum peel (2-A), 3-dimensional HPLC analysis (2B). (1) and (2) punicalagin isomers; (3) gallic acid; (4) ellagic acid.

In order to investigate components from the Punica granatum peel extract, the HPLC analysis was performed as shown in Fig. $4(\mathrm{~A}, \mathrm{~B})$. This result allowed gallic acid and ellagic acid to $\mathrm{be}^{17}$ components by the retention time of their standard compounds. ${ }^{18}$ And also the presence of punicalagin isomers could be deduced to be one of major components from the results of literature reported previously. ${ }^{19}$ Gallic acid was reported to have antibacterial activity against some intestinal bacteria and ellagic acid have anti-microbial activity. ${ }^{20}$ And punicalagin was reported to show anti-foodborn pathogens. ${ }^{21}$

These components may also provide antibacterial activity against Salmonella and provide a plausible explanation for the higher antibacterial activity of the EtOH extract.

In particular, we were known that the punicalagin derivatives were better antibacterial activity against Salmonella through in vitro study.

It is supposed that this activity is due to better inclusion effect by many hydroxyl groups consisting of punicalagin chemical structure.

In the next paper, we report in vitro study on the punicalagin derivatives in detail. 
KEYWORDS: Punica granatum peel, ellagic acid., gallic acid, punicalagin

Received February 8, 2013; Accepted March 25, 2013

\section{REFERENCES AND NOTES}

1. Singh R. P. ; Chidambara M. K. N. ; Jayaprakasha G. K. J Agric Food Chem 2002, 50, 81-6.

2. Sellappan S. ; Akoh C. C. ; Krewer G. J Agric Food Chem 2002, 50, 2432-2438.

3. Mertens-Talcott S. U. ; Jilma-Stohlawetz P. ; Rios J. ; Hingorani L, ; Derendorf H. J Agric Food Chem 2006, 54, 8956-61.

4. Wolfe K. ; Wu X. ; Liu R. H. J Agric Food Chem 2003, 51, 609-614.

5. Yang H. L.; Chang W. H.; Chia Y. C. ; Huang C. J. ; Lu F. J. ; Hsu H. K. ; Hseu. Y. C. Food Chem. Toxicol. 2006, 44, 1978-1988

6. Lu J. ; Wei Y. ; Yuan Q. J Chromatogr B Analyt Technol Biomed Life Sci. 2007, Sep, 15, 857

7. Gil M. I. ; Tomás-Barberán FA. ; Hess-Pierce B. ; Holcroft DM,Kader A. J Agric Food Chem 2000, 48, 4581-4589

8. Lansky E. P. ; Newman. R. A. J Ethnopharmacol. 2007, 109, 177-206.

9. Asres K. ; Bucar F. ; Knauder E. ; Yardley V. ; Kendrick H ; Croft SL. Phytother Res. 2001, Nov; 15(7), 613-7.

10. Burapadaja S ; Bunchoo A. Planta Med. 1995, Aug, 61(4), 365-6.

11. Liu M. ; Katerere D. R. ; Gray A. I. ; Seidel V. Fitoterapia. 2009, Sep, 80(6), 369-73. Epub 2009, May, 14.

12. Larrosa M. ; Tomas-Barberan F. A. ; Espin J. C. J Nutr. Biochem. 2006, 17, 611-625.

13. Lin C. C. ; Hsu Y. F. ; Lin T. C. Am. J Chin. Med. 1999, 27, 371-376.

14. Lin C. C. ; Hsu Y. F. ; Lin T. C. ; Hsu H. Y. Phytother. Res. 2001, 15, 206-212.

15. Chen P. S. ; Li J. H. ; Liu T. Y. ; Lin T. C. Cancer Lett. 2000, 152, 115-122.

16. Kwak H. M. ; Jeong H. H. ; Sohng B. H. ; Kim J. G. ; Lee J. M. ; Hur J. M. ; Song K. S. Korean Soc Appl Biol Chem. 2005, 48, 431-4.

17. Lu J. ; Wei Y. ; Yuan Q. J Chromatogr B. 2007. 857, 175-9.

18. Clinical and Laboratory Standards Institute. CLSI document M7-A5. Wayne, PA, 2000.

19. Ahn Y. J. ; Lee C. O. ; Kweon J. H. ; Ahn J. W., Park J. H. J Appl Microbiol. 1998, 84, 439-43.

20. Thiem B. ; Goslinska O. Fitoterapia. 2004, 75, 93-5.
21. Taguri T. ; Tanaka T. ; Kouno I. BiolPharm Bull. 2004, 27, 1965-9. 